\title{
Sirtuin-Activating Compounds (STACs) Alleviate D-Galactosamine/Lipopolysaccharide-Induced Hepatotoxicity in Rats: Involvement of Sirtuin 1 and Heme Oxygenase 1
}

\author{
M. K. KEMELO ${ }^{1}$, N. KUTINOVÁ CANOVÁ ${ }^{1}$, A. HORINEK ${ }^{2,3}$, H. FARGHALI ${ }^{1}$ \\ ${ }^{1}$ Institute of Pharmacology, First Faculty of Medicine, Charles University and General University \\ Hospital in Prague, Czech Republic, ${ }^{2}$ Institute of Biology and Medical Genetics, First Faculty of \\ Medicine, Charles University and General University Hospital in Prague, Czech Republic, ${ }^{3}$ Third \\ Medical Department, First Faculty of Medicine, Charles University and General University \\ Hospital in Prague, Czech Republic
}

Received September 13, 2016

Accepted November 4, 2016

On-line February 28, 2017

\begin{abstract}
Summary
Sirtuin activating compounds (STACs) attenuate various type of liver insults through mechanisms which are not fully understood. In the present study, we investigated the ameliorative potential of quercetin (natural polyphenol) and SRT1720 (synthetic SIRT1 activator) against D-galactosamine/lipopolysaccharide-induced hepatotoxicity (an experimental model of acute liver failure). Moreover, we compared and contrasted the roles of stress responsive enzymes, sirtuin 1 (SIRT1) and heme oxygenase 1 (HO-1) in hepatoprotection/ hepatotoxicity. Liver injury was induced in male Wistar rats by intraperitoneal injection of D-galactosamine $(400 \mathrm{mg} / \mathrm{kg})$ and lipopolysaccharide $(10 \mu \mathrm{g} / \mathrm{kg})$. Some animals were pretreated with quercetin (50 mg/ $\mathrm{kg}$ i.p.) or SRT1720 (5 mg/kg i.p.). Twenty-four hours later, the effects of these treatments were evaluated by biochemical studies and Western blot. D-GalN/LPS treatment upregulated HO-1 expression, downregulated SIRT1 expression, decreased AST:ALT ratio and markedly increased bilirubin, catalase and conjugated diene levels. Pretreatment of D-GalN/LPS rats with either quercetin or SRT1720 returned SIRT1 expression, $\mathrm{HO}-1$ expression and all the aforementioned markers towards normal. Collectively, these findings suggest that elevated HO-1 and low SIRT1 expressions are involved in the pathogenesis of D-GaIN/LPS-induced hepatotoxicity. Drugs that downregulate HO-1 and/or upregulate SIRT1 seem to have antihepatotoxic effects and need further exploration.
\end{abstract}

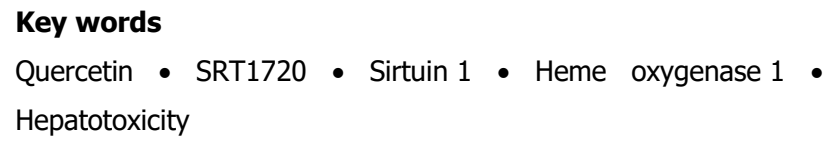

\section{Corresponding author}

M. K. Kemelo, Institute of Pharmacology, First Faculty of Medicine, Charles University and General University Hospital in Prague, Albertov 4, 12800 Prague 2, Czech Republic. E-mail: mighty.kemelo@lf1.cuni.cz

\section{Introduction}

Acute liver failure (ALF) refers to rapid deterioration in liver function leading to jaundice, coagulopathy and encephalopathy (Bernal and Wendon 2013). The etiology of ALF shows widespread geographic variation. In developed countries, infectious causes such as hepatitis A and B tend to be declining in incidence but drug-induced hepatotoxicity still predominates. For instance, in the United Kingdom, paracetamol overdose account for about $50 \%$ of the reported cases with as many as 90,000 patients presenting each year (Bateman et al. 2014). In about $15 \%$ of the cases, the cause remains indeterminate (Bernal et al. 2010). ALF is a medical emergency and requires prompt diagnosis and treatment. However, there are hardly any hepatoprotective drugs and the available few have doubtful efficacies. 
Medicinal plants, such as Silybum marianum and Glycyrrhiza glabra have been used for many generations to treat liver afflictions (Wang et al. 2007). Currently, patients still self-medicate with herbal products, despite inadequate scientific evidence to support their efficacies (Jacobs et al. 2002). One way of verifying the therapeutic potential of plant remedies is by extracting/isolating their active ingredients and testing them in controlled experimental settings. Amongst the numerous phytochemicals found in herbal plants, polyphenols have received much attention due to their protective effects against heart attacks (Rimm et al. 1996), cancers (Keli et al. 1996) and many liver diseases (Aller et al. 2015). This may, in part, explain stunning biogeographic concepts such as the 'French paradox' and some of the health benefits ascribed to moderate consumption of red wine (Catalgol et al. 2012).

It is unclear how polyphenols mediate the aforementioned health benefits. Currently, it is known that polyphenols exhibit anti-oxidant (Gülçin 2010), anti-microbial (Daglia 2012) and anti-inflammatory (García-Lafuente et al. 2009) properties. However, the molecular mechanism underlying these attractive features is still elusive. The widely accepted hypothesis is that polyphenols activate a histone deacetylase, SIRT1 (sirtuin 1). SIRT1 in turn acts as an 'on-off' transcription switch that regulates diverse array of substrates (including, but not limited to, p53, forkhead box proteins and DNA repair enzymes) which may be involved in the pathogenesis of many diseases (Farghali et al. 2013). These attractive features validate SIRT1 as a potential target in management of a wide spectrum of diseases.

In our institute, we have previously shown that dietary polyphenols have ameliorative effects against various liver insults such as high dose acetaminophen (APAP) and D-galactosamine/lipopolysaccharide (D-GalN/LPS). For instance, Černý et al. (2011) found curcumin pretreatment to have hepatoprotective effects in D-GalN/LPS treated rats through heme oxygenase 1 and nitric oxide synthase 2 modulation. Kemelo et al. demonstrated that EX-527 (SIRT1 inhibitor) diminishes the liver-protective effects of resveratrol against D-GalN/LPS-induced hepatotoxicity (Kemelo et al. 2014). Most recently, Wojnarova et al. found that resveratrol and CAY10591 (synthetic SIRT1 activator) increases SIRT1 activity and combat the cytotoxic effects of APAP both in vivo and in vitro (Wojnarová et al. 2015). Based on these promising results, we felt compelled to further clarify mechanisms underlying the cytoprotective effects of polyphenols.

The present study is an extension of our previous work, first reported in the European Review for Medical and Pharmacological Sciences (Kemelo et al. 2016). The study is designed to further shed light on the roles played by stress responsive enzymes, HO-1 and SIRT1, on the potential liver protective effects of putative SIRT1 activators, Quercetin and SRT1720.

\section{Methods}

\section{Chemicals}

Quercetin (2-(3,4-dihydroxyphenyl)-3,5,7trihydroxy-4H-1-benzopyran-4-one with HPLC purity of $>95 \%$ ), D-galactosamine hydrochloride, Lipopolysaccharide from Escherichia coli K-235, mouse monoclonal anti- $\beta$-Actin antibody and anti-mouse $\operatorname{IgG}$ (whole molecule)-peroxidase antibody were purchased from Sigma-Aldrich (Prague, Czech Republic). SRT1720 was purchased from Selleckchem (Munich, Germany). Heme oxygenase 1 and Stabilized Peroxidase conjugated goat anti-Mouse antibodies were purchased from Thermo Fisher Scientific (Prague, Czech Republic). SirT1 (1F3) mouse mAb antibody was from Cell Signaling Technology (Danvers, Massachusetts).

\section{Animals}

Outbred male Wistar rats (Velaz-Lysolaje, Czech Republic) of 250-350 g body weight were used. They were maintained under standard conditions $\left(22 \pm 2{ }^{\circ} \mathrm{C}\right.$ temperature, $50 \pm 10 \%$ relative humidity, 12-hour light-dark cycle) and given standard granulated diet and water ad libitum. All rats received humane care in accordance with the ethical guidelines of the First Faculty of Medicine, Charles University.

\section{Experimental design}

The animals were randomly assigned into six groups of eight animals and treated as shown in Table 1. All the drugs were administered intraperitoneally. The doses were selected based on our previous experiments with quercetin (Lekić et al. 2013) and SRT1720 (Kemelo et al. 2016).

After $24 \mathrm{~h}$, the animals were anesthetized with diethyl ether and euthanized by exsanguination. Blood samples were collected into heparinized tubes for biochemical analysis. Liver samples were excised and preserved in liquid nitrogen for Western blot study. 
Table 1. Experimental design: Quercetin and SRT1720 were dissolved in pure DMSO (Dimethyl sulfoxide). D-GalN (D-Galactosamine) and Lipopolysaccharide (LPS) were dissolved in physiological solution $(0.9 \% \mathrm{NaCl})$. All drugs were administered intraperitoneally, in a volume of $1 \mathrm{ml} / \mathrm{kg}$ body weight.

\begin{tabular}{ll} 
Group & \multicolumn{1}{c}{ Treatment } \\
\hline Group 1: Co & DMSO followed one hour later by physiological solution \\
Group 2: $Q$ & $50 \mathrm{mg} / \mathrm{kg}$ of quercetin followed one hour later by physiological solution \\
Group 3: SRT1720 & $5 \mathrm{mg} / \mathrm{kg}$ of SRT1720 followed one hour later by physiological solution \\
Group 4: D-GalN/LPS & DMSO followed one hour later by $400 \mathrm{mg} / \mathrm{kg}$ of D-GalN and $10 \mu \mathrm{g} / \mathrm{kg}$ of LPS \\
Group 5: $Q+D-G a l N / L P S$ & $50 \mathrm{mg} / \mathrm{kg}$ of quercetin followed one hour later by $400 \mathrm{mg} / \mathrm{kg}$ of D-GalN and \\
& $10 \mu \mathrm{g} / \mathrm{kg}$ of LPS \\
Group 6: SRT1720 $+D-G a l N / L P S$ & $5 \mathrm{mg} / \mathrm{kg}$ of SRT1720 followed one hour later by $400 \mathrm{mg} / \mathrm{kg}$ of D-GalN and \\
& $10 \mu \mathrm{g} / \mathrm{kg}$ of LPS
\end{tabular}

\section{Biochemical investigation}

Plasma levels of alanine aminotransferase (ALT), total bilirubin and aspartate aminotransferase (AST) were measured using customized diagnostic kits according to the manufacturer's instructions (Analyticon, Lichtenfels, Germany). Levels of catalase in plasma and conjugated dienes in liver homogenate were measured as previously described by Farghali et al. (2009).

\section{Immunoblotting}

Liver samples were lysed and homogenized in NP40 lysis buffer. After centrifugation (12,000 rpm, $\left.15 \mathrm{~min}, 4{ }^{\circ} \mathrm{C}\right)$ of the homogenized samples, protein concentration of the supernatant was determined using BIO-RAD DC protein assay kit (BIO-RAD, Hercules, CA). Equal amounts of protein were fractionated on an SDS-PAGE gel and transferred to a nitrocellulose membrane. The membranes were incubated in Tris-buffered saline (TBS) containing $5 \%$ non-fat milk (for $1 \mathrm{~h}$ at room temperature) and then in primary antibodies overnight at $4{ }^{\circ} \mathrm{C}$ : HO-1 $(1: 1,000)$, SIRT1 $(1: 1,000)$ and Beta actin $(1: 5,000)$. The following day, the membranes were washed in TBS-Tween and incubated for $1 \mathrm{~h}$ at room temperature with the corresponding secondary antibody: goat anti-mouse stabilized peroxidase conjugate $(1: 1,000)$ or anti-mouse $\operatorname{IgG}$ (whole molecule)-peroxidase $(1: 80,000)$. Bands were detected using Molecular Imager VersaDoc ${ }^{\mathrm{TM}}$ MP 5000 System and the protein density was measured using the Quantity One 1-D Analysis Software (Bio-Rad, Prague, Czech Republic).

\section{Statistical analysis}

Data are expressed as mean \pm SEM (standard error of mean) of at least five animals per group. Significance of differences between the groups was determined by one-way ANOVA followed by TukeyKramer comparison test. $\mathrm{p}<0.05$ was considered to indicate a statistically significant difference.

\section{Results}

Our first objective was to reconfirm the hepatotoxic effects of D-GalN/LPS (Table 2 and Fig. 1). Compared to the negative control, D-GalN/LPS significantly decreased AST:ALT ratio. Moreover, D-GalN/LPS markedly increased bilirubin, catalase and conjugated diene levels. These findings suggest profound oxidative damage and lipoperoxidation in the liver.

Secondly, we investigated if quercetin and SRT1720 might have any protective effects against D-GalN/LPS-induced hepatotoxicity. Pretreatments of D-GalN/LPS rats with either quercetin or SRT1720 significantly increased the AST:ALT ratio towards normal and decreased bilirubin, conjugated diene and catalase levels, compared to the D-GalN/LPS treated group. This shows that quercetin and SRT1720 were effective in combating the liver toxic effects of D-GalN/LPS.

Thirdly, we investigated if quercetin, SRT1720 and D-GalN/LPS treatments might have any effect on HO-1 expression. For this, we performed Western blot analysis (Fig. 2). Alone, quercetin and SRT1720 moderately increased HO-1 expression relative to the negative control by 4.2-fold and 2.9-fold respectively. D-GalN/LPS treatment caused an even greater upregulation of HO-1 expression (of 7.8-fold relative to the control). Pretreatment of D-GalN/LPS rats with 
quercetin and SRT1720 significantly decreased HO-1 expression relative to the D-GalN/LPS group. Quercetin pretreatment decreased HO-1 expression by 4.8 -fold and SRT1720 by 4.7 -fold.

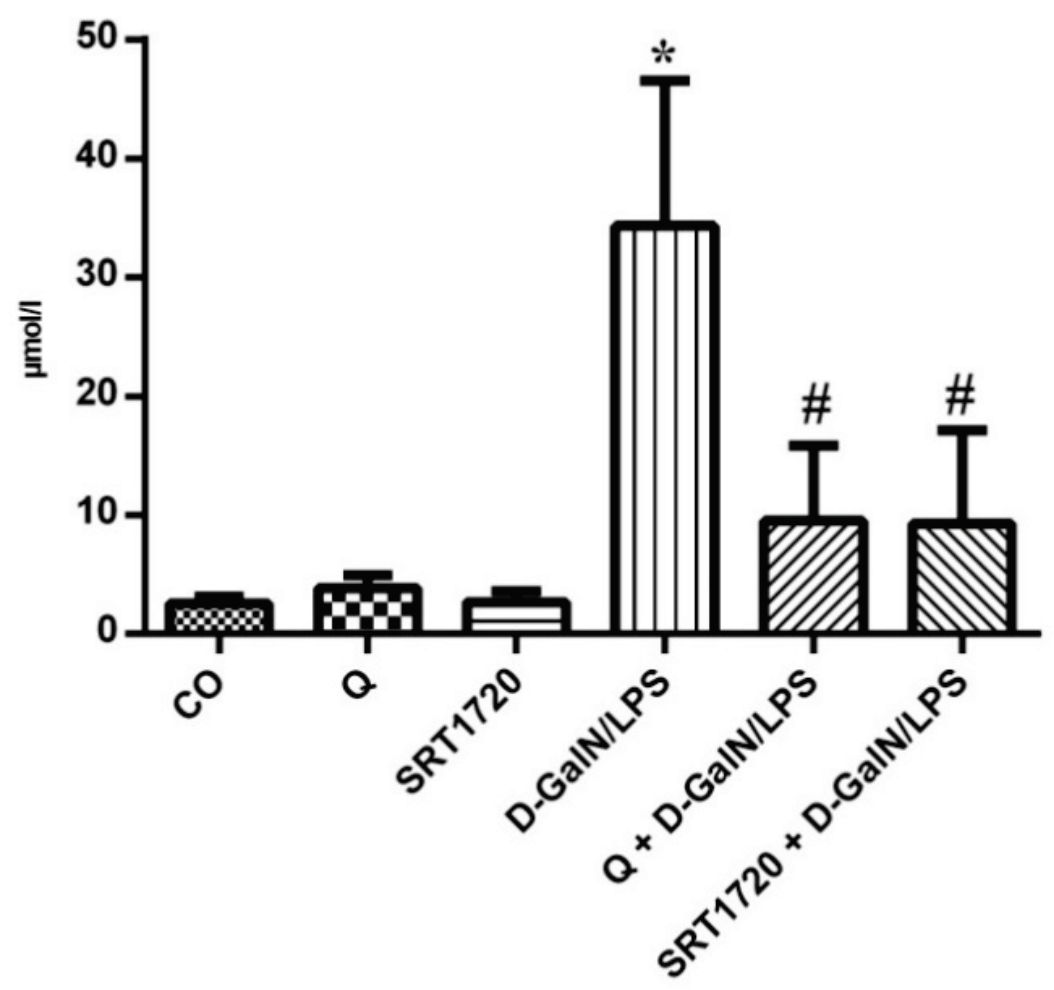

Fig. 1. Effects of quercetin and SRT1720 pretreatments in lipopolysaccharideinduced hepatitis in D-galactosamine sensitized (D-GalN/LPS) rats on plasma levels of total bilirubin. Co: negative control, vehicle only; Q: quercetin $50 \mathrm{mg} / \mathrm{kg}$; SRT1720: SRT1720 $5 \mathrm{mg} / \mathrm{kg}$; D-GalN/LPS: D-galactosamine $400 \mathrm{mg} / \mathrm{kg}$ + Lipopolysaccharide $10 \mu \mathrm{g} / \mathrm{kg} ; \mathrm{Q}$ + D-GalN/LPS: Combination of $\mathrm{Q}$ and D-GalN/LPS; SRT1720 + D-GalN/LPS: Combination of SRT1720 and D-GalN/LPS. * Indicates significant values $(p \leq 0.05)$ compared to the negative control group (vehicle only); \# Indicates significant values $(p \leq 0.05)$ compared to the D-GalN/LPS group. The results are expressed as means \pm SEM, $n=5-8$.

Table 2. Effects of quercetin and SRT1720 pretreatments in lipopolysaccharide-induced hepatitis in D-galactosamine sensitized (D-GaIN/LPS) rats on AST:ALT ratio, the levels of catalase in plasma and conjugated dienes in liver homogenate.

\begin{tabular}{lccc} 
Group & AST: ALT ratio & $\begin{array}{c}\text { Catalase } \\
\text { (nmol/l) }\end{array}$ & $\begin{array}{c}\text { Conjugated dienes } \\
\text { (nmol/mg protein) }\end{array}$ \\
\hline Co & $2.17 \pm 0.45$ & $41.2 \pm 11.60$ & $1.52 \pm 0.37$ \\
$Q$ & $2.46 \pm 1.03$ & $37.8 \pm 4.90$ & $1.18 \pm 0.32$ \\
SRT1720 & $2.21 \pm 0.27$ & $29.25 \pm 7.20$ & $2.07 \pm 1.01$ \\
D-GalN/LPS & $0.29 \pm 0.11^{*}$ & $130.2 \pm 3.50^{*}$ & $3.56 \pm 0.89^{*}$ \\
$Q+$ D-GalN/LPS & $1.92 \pm 0.45^{\#}$ & $79.2 \pm 16.80^{\#}$ & $1.53 \pm 0.45^{\#}$ \\
SRT1720+D-GalN/LPS & $1.03 \pm 0.49^{\#}$ & $99.8 \pm 14.20^{* \#}$ & $1.88 \pm 0.35^{\#}$ \\
\hline
\end{tabular}

Co: negative control, vehicle only; Q: quercetin $50 \mathrm{mg} / \mathrm{kg} ; \quad S R T 1720$ : SRT1720 $5 \mathrm{mg} / \mathrm{kg} ;$ D-GalN/LPS: D-galactosamine $400 \mathrm{mg} / \mathrm{kg}+$ Lipopolysaccharide $10 \mu \mathrm{g} / \mathrm{kg} ; \mathrm{Q}+\mathrm{D}-$ GalN/LPS: Combination of Q and D-GalN/LPS; SRT1720 + D-GalN/LPS: Combination of SRT1720 and D-GalN/LPS. " Indicates significant values $(p \leq 0.05)$ compared to the negative control group (vehicle only); ${ }^{\#}$ Indicates significant values $(p \leq 0.05)$ compared to the $D-G a I N / L P S$ group. The results are expressed as means $\pm S E M, n=5-8$.

Finally, we investigated how the aforementioned drugs might affect SIRT1 protein expression (Fig. 3). Consistent with our previous findings (Kemelo et al. 2016), we found that quercetin and SRT1720 treatments markedly increased SIRT1 expression, compared to the negative control. Conversely, D-GalN/LPS significantly downregulated SIRT1 protein expression relative to the negative control. Pretreatment of the D-GalN/LPS rats with either quercetin or SRT1720 restored SIRT1 expression to normal. 
A

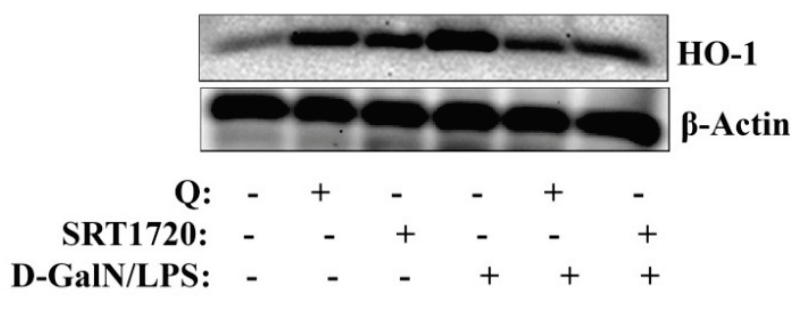

B

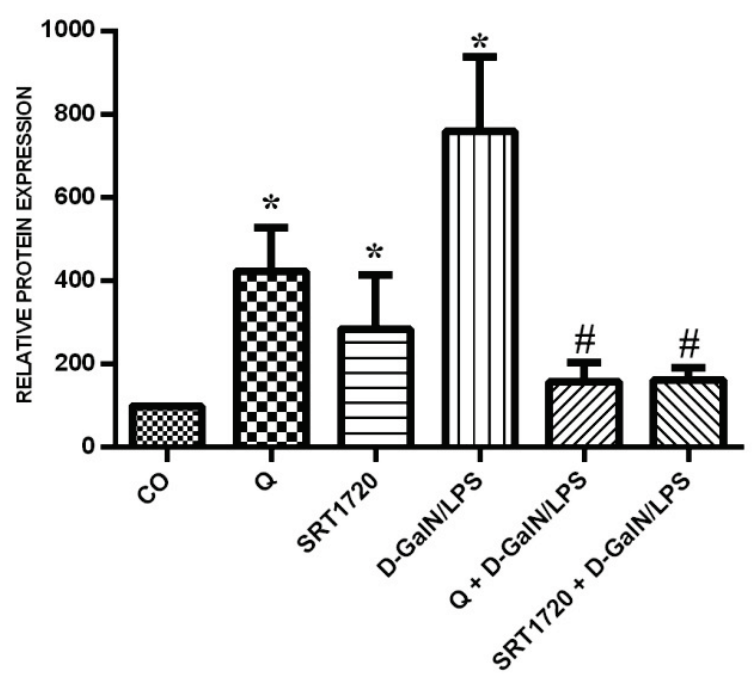

Fig. 2. Effects of quercetin and SRT1720 pretreatments on HO-1 protein expression in lipopolysaccharide-induced hepatitis in D-galactosamine sensitized (D-GalN/LPS) rats. Beta actin used as an endogenous control. (A) Representative Western blot image. (B) Protein expression relative to the control group. Co: negative control, vehicle only; Q: quercetin $50 \mathrm{mg} / \mathrm{kg}$; SRT1720: SRT1720 $5 \mathrm{mg} / \mathrm{kg}$; D-GalN/LPS: D-galactosamine $400 \mathrm{mg} / \mathrm{kg}+$ Lipopolysaccharide $10 \mu \mathrm{g} / \mathrm{kg}$; Q + D-GaIN/LPS: Combination of Q and D-GalN/LPS; SRT1720 + D-GaIN/LPS: Combination of SRT1720 and D-GalN/LPS. * Indicates significant values $(p \leq 0.05)$ compared to the negative control group (vehicle only); \#Indicates significant values $(p \leq 0.05)$ compared to the $D-G a I N / L P S$ group. The results are expressed as means \pm SEM, $\mathrm{n}=5$.

\section{Discussion}

The present study highlights the capacity of quercetin and SRT1720 in ameliorating D-GalN/LPSinduced hepatotoxicity. As already reported elsewhere, D-GalN/LPS causes severe liver toxicity that closely resembles ALF seen clinically (Liu et al. 2008). In this model, lipopolysaccharide (LPS), an endotoxin, accumulates primarily in tissues rich in cells of the reticuloendothelial system such as the liver (Nolan 1981). It then interacts with hepatic macrophages and triggers local damage through a variety of cytotoxic agents such as interleukin-1, tumor necrosis factor (TNF) and reactive oxygen species (ROS) (Hsu and Wen 2002).
A

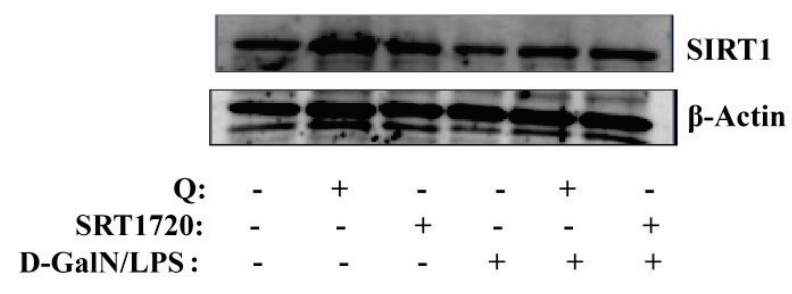

B

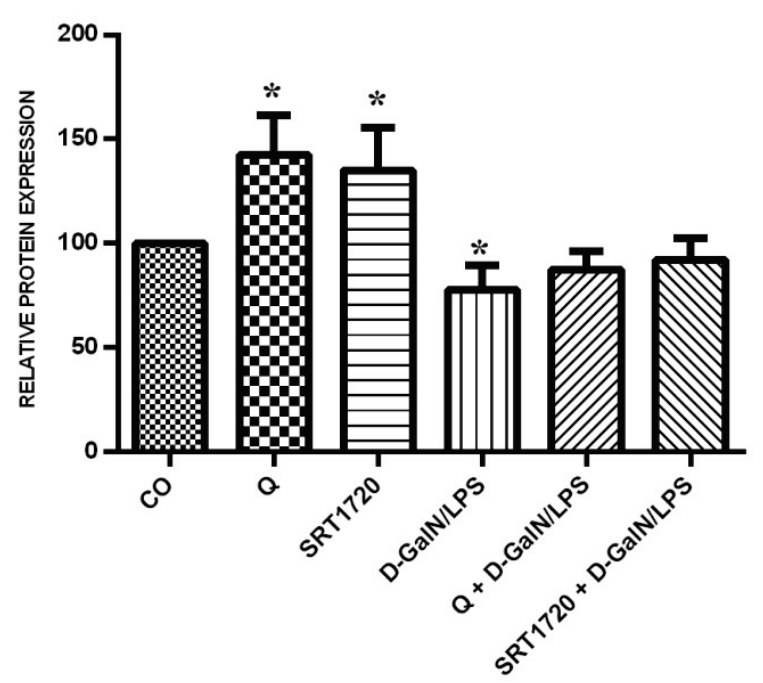

Fig. 3. Effects of quercetin and SRT1720 pretreatments on SIRT1 protein expression in lipopolysaccharide-induced hepatitis in D-galactosamine sensitized (D-GalN/LPS) rats. Beta actin used as an endogenous control. (A) Representative Western blot image. (B) Protein expression relative to the control group. Co: negative control, vehicle only; Q: quercetin $50 \mathrm{mg} / \mathrm{kg}$; SRT1720: SRT1720 $5 \mathrm{mg} / \mathrm{kg}$; D-GalN/LPS: D-galactosamine $400 \mathrm{mg} / \mathrm{kg}+$ Lipopolysaccharide $10 \mu \mathrm{g} / \mathrm{kg}$; Q + D-GalN/LPS: Combination of Q and D-GalN/LPS; SRT1720 + D-GalN/LPS: Combination of SRT1720 and D-GaIN/LPS. * Indicates significant values $(p \leq 0.05)$ compared to the negative control group (vehicle only); \# Indicates significant values $(p \leq 0.05)$ compared to the D-GalN/LPS group. The results are expressed as means \pm SEM, $\mathrm{n}=5$.

D-Galactosamine (D-GalN), on the other hand, depletes uridine nucleotide pool, inhibits protein synthesis in hepatocytes and sensitizes the liver to the cytotoxic effects of LPS (Silverstein 2004). A cocktail of these two drugs produces extensive liver damage and markedly increases the aminotransferase levels in plasma. Another reliable index of hepatotoxicity is the AST:ALT ratio, first discovered by Fernando De Ritis in 1957 (Botros and Sikaris 2013). As previously demonstrated, D-GalN/LPS treatment increases both transaminases (Kemelo et al. 2016), with the greatest effect on ALT, hence the ratio plummets. In addition to transaminases, increase in conjugated dienes and catalase indicate lipoperoxidation and oxidative injury in the liver. 
Furthermore, lipopolysaccharide or ROS can induce HO-1 to produce peroxyl radical scavenging metabolites, biliverdin and bilirubin. It seems, therefore, reasonable to postulate that increase in HO-1 and bilirubin might be an adaptive mechanism to overcome stress. However, bilirubin can also be cytotoxic, especially at high concentrations. For instance, it can impair protein synthesis (Basu et al. 2014), disrupt membrane fluidity (Rodrigues et al. 2002), inhibit membrane-bound proteins such as ATPases (Kashiwamata et al. 1979) and trigger apoptosis (Rodrigues et al. 2002) (Oakes and Bend 2005). In particular, Molle et al. demonstrated that D-GalN/TNF challenge of mice upregulates HO-1, markedly increases total bilirubin and causes massive apoptosis of hepatocytes. But, pretreatment with a HO-1 inhibitor, Sn (IV) protoporphyrin IX dichloride, lowers total bilirubin levels and significantly improves the outcome (van Molle and Libert 2003). Consistent with our results, these findings provide a possible link between high bilirubin levels and liver toxicity. Alongside HO-1, SIRT1 activity can be affected by oxidative stress at different levels. For instance, ROS can decrease SIRT1 expression by covalently modifying and marking it for proteasomal degradation (Caito et al. 2010). Apart from gene expression, some studies have shown that oxidative stress can over-activate PARP (Poly [ADP-ribose] polymerase), deplete cellular NAD + stores and decreased SIRT1 deacetylase activity (Braidy et al. 2011). Collectively, this makes it most probable that D-GalN/LPS rats in our study were also deprived of potentially therapeutic SIRT1 effects such as activation of Ku70 (involved in DNA repair) (Jeong et al. 2007) and Fox03 (which regulates antioxidant enzymes) (Brunet $e t$ al. 2004).

The antioxidant properties of quercetin are well-established. For instance, the ancient custom of preserving lard by mixing it with onion may be based on prevention of lipid oxidation by quercetin (SunWaterhouse et al. 2013). Moreover, the consumption of quercetin-rich diet have protective effects against oxidative stress-related diseases such as Alzheimer's and coronary heart diseases (Nishimuro et al. 2015). Numerous experimental studies have shown that quercetin can ameliorate different kinds of liver insults (carbon tetrachloride (Amália et al. 2007), paracetamol (Janbaz et al. 2004) and ethanol (Chen 2010)) through diverse mechanisms ranging from direct scavenging of free radicals (Jovanovic and Simic 2000) to interaction with various enzyme systems (Kobori et al. 2015). In this study, quercetin mitigated the cytotoxic effects of D-GalN/LPS, in part, through decreasing HO-1 expression and bilirubin level. Despite the fact that total bilirubin may be toxic at high levels, there is some evidence that it might be cytoprotective at micromolar concentrations. For instance, in vitro, studies have shown that both conjugated and unconjugated bilirubin can protect cells against artificially generated peroxyl radicals (Wu et al. 1996). In vivo, many experiments have shown that hepatoprotective drugs such as silymarin (Madkour and Abdel-Daim 2013) and Aspalathus linearis (Ulicná et al. 2003) act, in part, through lowering total bilirubin levels towards normal. All these findings suggest that bilirubin is a 'double-edged sword' with concentrationdependent toxic and protective effects.

Liver-protective effects of quercetin may also be SIRT1 mediated. Like HO-1, but in reverse quercetin pretreatment restored SIRT1 expression to normal. Taken together, a pattern appears to emerge: it seems as if quercetin triggers homeostatic mechanisms in D-GalN/LPS rats which ensure that both HO-1 and SIRT1 expressions return to reasonable physiologic limits. However, the controversy of SIRT1 activation by polyphenols has drawn much attention from the scientific community in the last couple of years. Whether polyphenols directly activate SIRT1 (Howitz et al. 2003), indirectly activate SIRT1 through other target molecules such as AMP-activated protein kinase (Kang et al. 2013) or act independent of SIRT1 (Zhang 2006) is still elusive. In order to address this uncertainty, we pretreated some rats with SRT1720, a structurally distinct but extremely potent STAC (Milne et al. 2007). To our surprise, SRT1720 similarly restored SIRT1 expression to normal in D-GalN/LPS rats. How these putative SIRT1 activators upregulate SIRT1 expression is not clear. However, some studies have shown that STACs activate Fox01 (Huang et al. 2013), which can positively feedback SIRT1 expression (Xiong et al. 2006). These parallel liverprotective effects between quercetin and SRT1720 and their effects on SIRT1, as well as HO-1, expression strongly suggest a common mechanism of action.

In conclusion, we have demonstrated that Quercetin and SRT1720 pretreatments are ameliorative against D-GalN/LPS-induced hepatotoxicity. Excessively high HO-1 and concomitantly low SIRT1 expression levels seen in D-GalN/LPS treated rats are pathologic. Drugs that downregulate HO-1 and/or upregulate SIRT1, such as STACs, seems to be hepatoprotective and need further exploration. 


\section{Conflict of Interest}

There is no conflict of interest.

\section{Acknowledgements}

This study was supported by the research program PRVOUK-P25/LF1/2 and institutional grant GAUK916314. The authors would like to thank Libuše Šlehobrová for her skillful technical assistance.

\section{References}

ALLER R, IZAOLA O, GÓMEZ S, TAFUR C, GONZÁLEZ G, BERROA E, MORA N, GONZÁLEZ JM, DE LUIS DA: Effect of silymarin plus vitamin $\mathrm{E}$ in patients with non-alcoholic fatty liver disease. A randomized clinical pilot study. Eur Rev Med Pharmacol Sci 19: 3118-3124, 2015.

AMÁLIA PM, POSSA MN, AUGUSTO MC, FRANCISCA LS: Quercetin prevents oxidative stress in cirrhotic rats. Dig Dis Sci 52: 2616-2621, 2007.

BASU S, DE D, DEV KHANNA H, KUMAR A: Lipid peroxidation, DNA damage and total antioxidant status in neonatal hyperbilirubinemia. $J$ Perinatol 34: 519-523, 2014.

BATEMAN DN, CARROLL R, PETTIE J, YAMAMOTO T, ELAMIN ME, PEART L, DOW M, COYLE J, CRANFIELD KR, HOOK C, SANDILANDS EA, VEIRAIAH A, WEBB D, GRAY A, DARGAN PI, ET AL.: Effect of the UK's revised paracetamol poisoning management guidelines on admissions, adverse reactions and costs of treatment. Br J Clin Pharmacol 78: 610-618, 2014.

BERNAL W, AUZINGER G, DHAWAN A, WENDON J: Acute liver failure. Lancet 376: 190-201, 2010.

BERNAL W, WENDON J: Acute liver failure. N Engl J Med 369: 2525-2534, 2013.

BOTROS M, SIKARIS KA: The de ritis ratio: the test of time. Clin Biochem Rev 34: 117-130, 2013.

BRAIDY N, GUILLEMIN GJ, MANSOUR H, CHAN-LING T, POLJAK A, GRANT R: Age related changes in NAD+ metabolism oxidative stress and Sirt1 activity in Wistar rats. PLoS One 6: e19194, 2011.

BRUNET A, SWEENEY LB, STURGILL JF, CHUA KF, GREER PL, LIN Y, TRAN H, ROSS SE, MOSTOSLAVSKY R, COHEN HY, ET AL.: Stress-dependent regulation of FOXO transcription factors by the SIRT1 deacetylase. Science 303: 2011-2015, 2004.

CAITO S, RAJENDRASOZHAN S, COOK S, CHUNG S, YAO H, FRIEDMAN AE, BROOKES PS, RAHMAN I: SIRT1 is a redox-sensitive deacetylase that is post-translationally modified by oxidants and carbonyl stress. FASEB J 24: 3145-3159, 2010.

CATALGOL B, BATIREL S, TAGA Y, OZER NK: Resveratrol: French paradox revisited. Front Pharmacol 3: 141, 2012.

CERNÝ D, LEKIĆ N, VÁŇOVÁ K, MUCHOVÁ L, HOŘÍNEK A, KMONÍČKOVÁ E, ZÍDEK Z, KAMENÍKOVÁ L, FARGHALI H: Hepatoprotective effect of curcumin in lipopolysaccharide/-galactosamine model of liver injury in rats: Relationship to HO-1/CO antioxidant system. Fitoterapia 82: 786-791, 2011.

CHEN X: Protective effects of quercetin on liver injury induced by ethanol. Pharmacogn Mag 6: 135-141, 2010.

DAGLIA M: Polyphenols as antimicrobial agents. Curr Opin Biotechnol 23: 174-181, 2012.

FARGHALI H, CERNÝ D, KAMENÍKOVÁ L, MARTÍNEK J, HORÍNEK A, KMONÍCKOVÁ E, ZÍDEK Z: Resveratrol attenuates lipopolysaccharide-induced hepatitis in d-galactosamine sensitized rats: Role of nitric oxide synthase 2 and heme oxygenase-1. Nitric Oxide 21: 216-225, 2009.

FARGHALI H, KUTINOVÁ CANOVÁ N, LEKIĆ N: Resveratrol and related compounds as antioxidants with an allosteric mechanism of action in epigenetic drug targets. Physiol Res 62: 1-13, 2013.

GARCÍA-LAFUENTE A, GUILLAMÓN E, VILLARES A, ROSTAGNO MA, MARTÍNEZ JA: Flavonoids as anti-inflammatory agents: Implications in cancer and cardiovascular disease. Inflamm Res 58: 537-552, 2009.

GÜLÇIN I: Antioxidant properties of resveratrol: a structure-activity insight. Innov Food Sci Emerg Technol 11: 210-218, 2010.

HOWITZ KT, BITTERMAN KJ, COHEN HY, LAMMING DW, LAVU S, WOOD JG, ZIPKIN RE, CHUNG P, KISIELEWSKI A, ZHANG LL, SCHERER B, SINCLAIR DA: Small molecule activators of sirtuins extend Saccharomyces cerevisiae lifespan. Nature 425: 191-196, 2003. 
HSU HY, WEN MH: Lipopolysaccharide-mediated reactive oxygen species and signal transduction in the regulation of interleukin-1 gene expression. J Biol Chem 277: 22131-22139, 2002.

HUANG CY, CHAN CY, CHOU IT, LIEN CH, HUNG HC, LEE MF: Quercetin induces growth arrest through activation of FOXO1 transcription factor in EGFR-overexpressing oral cancer cells. $J$ Nutr Biochem 24: 1596-1603, 2013.

JACOBS BP, DENNEHY C, RAMIREZ G, SAPP J, LAWRENCE VA: Milk thistle for the treatment of liver disease. Am J Med 113: 506-515, 2002.

JANBAZ K, SAEED S, GILANI A: Studies on the protective effects of caffeic acid and quercetin on chemical-induced hepatotoxicity in rodents. Phytomedicine 11: 424-430, 2004.

JEONG J, JUHN K, LEE H, KIM SH, MIN BH, LEE KM, CHO MH, PARK GH, LEE KH: SIRT1 promotes DNA repair activity and deacetylation of Ku70. Exp Mol Med 39: 8-13, 2007.

JOVANOVIC SV, SIMIC MG: Antioxidants in nutrition. Ann N Y Acad Sci 899: 326-334, 2000.

KANG OH, KIM SB, SEO YS, JOUNG DK, MUN SH, CHOI JG, LEE YM, KANG DG, LEE HS, KWON DY: Curcumin decreases oleic acid-induced lipid accumulation via AMPK phosphorylation in hepatocarcinoma cells. Eur Rev Med Pharmacol Sci 17: 2578-2586, 2013.

KASHIWAMATA S, GOTO S, SEMBA RK, SUZUKI FN: Inhibition by bilirubin of $(\mathrm{Na}++\mathrm{K}+$ )-activated adenosine triphosphatase and $\mathrm{K}+$-activated p-nitrophenylphosphatase activities of NaI-treated microsomes from young rat cerebrum. J Biol Chem 254: 4577-4584, 1979.

KELI SO, HERTOG MG, FESKENS EJ, KROMHOUT D: Dietary flavonoids, antioxidant vitamins, and incidence of stroke: the Zutphen study. Arch Intern Med 156: 637-642, 1996.

KEMELO MK, HORINEK A, CANOVÁ NK, FARGHALI H: Comparative effects of Quercetin and SRT1720 against D-galactosamine/lipopolysaccharide-induced hepatotoxicity in rats: biochemical and molecular biological investigations. Eur Rev Med Pharmacol Sci 20: 363-371, 2016.

KEMELO MK, WOJNAROVÁ L, KUTINOVÁ CANOVÁ N, FARGHALI H: D-galactosamine/lipopolysaccharideinduced hepatotoxicity downregulates sirtuin 1 in rat liver: role of sirtuin 1 modulation in hepatoprotection. Physiol Res 63: 615-623, 2014.

KOBORI M, TAKAHASHI Y, AKIMOTO Y, SAKURAI M, MATSUNAGA I, NISHIMURO H, NISHIMUROA H, IPPOUSHIA K, OIKEA H, OHNISHI-KAMEYAMAA M: Chronic high intake of quercetin reduces oxidative stress and induces expression of the antioxidant enzymes in the liver and visceral adipose tissues in mice. J Funct Foods 15: 551-560, 2015.

LEKIĆ N, CANOVÁ NK, HOŘíNEK A, FARGHALI H: The involvement of heme oxygenase 1 but not nitric oxide synthase 2 in a hepatoprotective action of quercetin in lipopolysaccharide-induced hepatotoxicity of d-galactosamine sensitized rats. Fitoterapia 87: 20-26, 2013.

LIU LM, ZHANG JX, LUO J, GUO HX, DENG H, CHEN JY, SUN SL: A role of cell apoptosis in lipopolysaccharide (LPS)-induced nonlethal liver injury in d-galactosamine (d-GalN)-sensitized rats. Dig Dis Sci 53: 1316-1324, 2008.

MADKOUR FF, ABDEL-DAIM MM: Hepatoprotective and antioxidant activity of Dunaliella salina in paracetamolinduced acute toxicity in rats. Indian J Pharm Sci 75: 642-648, 2013.

MILNE JC, LAMBERT PD, SCHENK S, CARNEY DP, SMITH JJ, GAGNE DJ, JIN L, BOSS O, PERNI RB, VU CB, ET AL.: Small molecule activators of SIRT1 as therapeutics for the treatment of type 2 diabetes. Nature 450: 712-716, 2007.

NISHIMURO H, OHNISHI H, SATO M, OHNISHI-KAMEYAMA M, MATSUNAGA I, NAITO S, IPPOUSHI K, OIKE H, NAGATA T, AKASAKA H, SAITOH S, SHIMAMOTO K, KOBORI M: Estimated daily intake and seasonal food sources of quercetin in Japan. Nutrients 7: 2345-2358, 2015.

NOLAN JP: Endotoxin, reticuloendothelial function, and liver injury. Hepatology 1: 458-465, 1981.

OAKES GH, BEND JR: Early steps in bilirubin-mediated apoptosis in murine hepatoma (Hepa 1c1c7) cells are characterized by aryl hydrocarbon receptor-independent oxidative stress and activation of the mitochondrial pathway. J Biochem Mol Toxicol 19: 244-255, 2005.

RIMM EB, KATAN MB, ASCHERIO A, STAMPFER MJ, WILLETT WC: Relation between intake of flavonoids and risk for coronary heart disease in male health professionals. Ann Intern Med 125: 384-389, 1996. 
RODRIGUES C, SOLÁ S, BRITES D: Bilirubin induces apoptosis via the mitochondrial pathway in developing rat brain neurons. Hepatology 35: 1186-1195, 2002.

RODRIGUES CM, SOLÁ S, BRITO MA, BRITES D, MOURA JJ: Bilirubin directly disrupts membrane lipid polarity and fluidity, protein order, and redox status in rat mitochondria. J Hepatol 36: 335-341, 2002.

SILVERSTEIN R: D-Galactosamine lethality model: scope and limitations. J Endotoxin Res 10: 147-162, 2004.

SUN-WATERHOUSE D, XUE D, WADHWA S: Effects of added phenolics on the lipid deterioration and antioxidant content of deep-fried potato fritters. Food Bioprocess Technol 6: 3256-3265, 2013.

ULICNÁ O, GREKSÁK M, VANCOVÁ O, ZLATOS L, GALBAVÝ S, BOZEK P, NAKANO M: Hepatoprotective effect of rooibos tea (Aspalathus linearis) on CCl4-induced liver damage in rats. Physiol Res 52: 461-466, 2003.

VAN MOLLE W, LIBERT C: Bilirubin release induced by tumor necrosis factor in combination with galactosamine is toxic to mice. Cytokine 23: 94-100, 2003.

WANG R, KONG J, WANG D, LIEN LL, LIEN EJ: A survey of Chinese herbal ingredients with liver protection activities. Chin Med 2: 5, 2007.

WOJNAROVÁ L, KUTINOVÁ CANOVÁ N, FARGHALI H, KUČERA T: Sirtuin 1 modulation in rat model of acetaminophen-induced hepatotoxicity. Physiol Res 64 (Suppl 4): S477-S487, 2015.

WU TW, FUNG KP, WU J, YANG CC, WEISEL RD: Antioxidation of human low density lipoprotein by unconjugated and conjugated bilirubins. Biochem Pharmacol 51: 859-862, 1996.

XIONG S, SALAZAR G, PATRUSHEV N, ALEXANDER RW: FoxO1 mediates an autofeedback loop regulating SIRT1 expression. J Biol Chem 286: 5289-5299, 2011.

ZHANG J: Resveratrol inhibits insulin responses in a SirT1-independent pathway. Biochem J 397: 519-527, 2006. 